\title{
Investigations on Thermal Conductivity of Palm Fibre Reinforced Polyester Composites
}

\author{
Ramesh Chandra Mohapatra ${ }^{1}$, Antaryami Mishra ${ }^{2}$, Bibhuti Bhushan \\ Choudhury ${ }^{3}$ \\ ${ }^{1}$ Government College of Engineering, Keonjhar- 758002, India, \\ ${ }^{2}$ Indira Gandhi Institute of Technology, Sarang-759146, India \\ ${ }^{3}$ Indira Gandhi Institute of Technology, Sarang-759146, India
}

\begin{abstract}
The palm fibre reinforced polyester composites (PFRP) have been prepared by using hand-lay- up technique. The thermal conductivity of the palm fibre reinforced polyester composites at different volume fractions of the fibre is determined experimentally by using Lee's apparatus. The principle of heat transfer by conduction through a bad conductor is equal to the quantity of heat transfer by radiation from metallic disc has been applied. The experimental results shows that the thermal conductivity of the composite increases with increase in fibre percentage. Experimental results are compared with rule of mixture model, parallel model and Maxwell model to describe the variation of the thermal conductivity versus the volume fraction of the fibre. All three models exhibited results close to each other at low fibre content. It has been found that the errors associated with rule of mixtures, parallel model and Maxwell's correlations with respect to experimental ones lie in the range of $33-79 \%, 28$ to $73 \%$ and 31 to $75 \%$ respectively.
\end{abstract}

Keywords: Error Analysis, Lees Apparatus, Palmfibre-Polyster composites, Thermal Conductivity,

\section{Introduction}

Recently, thermoplastic and thermoset polymers are combined with natural fillers to produce the composites, which possess better strength and good resistance to fracture. Natural fiber as a replacement to synthetic fibre in polymer matrix is the focus of many scientists and engineers. The reason for focus on natural fiber reinforced polymer matrix is because of its low cost, eco-friendly, low energy consumption, non abrasive nature, and good insulator of heat and sound. Major industries such as automotive, construction and packaging have shown enormous interest in the development of new bio-composite materials and are currently engaged in searching for new and alternate products to synthetic fibre reinforced composites. Unsaturated polyesters are extremely versatile in properties and applications. These are popular thermosets used as the polymer matrix in composites.

\section{Review of Literature}

Effective thermal conductivity is an important characteristic of heat transfer properties of materials. The temperature field in composite materials cannot be determined unless the thermal conductivities of the media are known. Numerous theoretical and experimental approaches have been developed to determine the precise value of this parameter. Maxwell [1] studied the effective thermal conductivity of heterogeneous materials. By solving Laplace's equation, the effective thermal conductivity of a random suspension was determined for sphere within a continuous medium. Agrawal et al. [2] studied the thermal conductivity and thermal diffusivity of oil-palm-fibre-reinforced untreated and differently treated composites using transient plane source technique at room temperature. All the silane and alkali treatments of the fibres increased the thermal conductivity and thermal diffusivity of the composites in comparison with the acetylated composite. Saxena et al. [3] studied the variation of thermal conductivity and thermal diffusivity of banana fibre reinforced polyester composite caused by addition of glass fibre. They observed that the thermal conductivity of composites increased when compared to neat matrix. However, the thermal conductivity of the composites with increased percentage of glass fibre decreases in comparison to composite of pure banana, Fu and Mai [4] studied the effect of fibre length and fibre orientation angle on the thermal conductivity of short carbon fibre reinforced composite materials. The thermal conductivity of the composite increased with fibre length but decreased with fibre orientation angle with respect to specified measured direction. Mangal et al. [5] studied the effect of volume fraction of pine apple leaf fibre on thermal properties of the composite using transient plane source technique. Increasing the fibre content in the matrix decreases the thermal conductivity and thermal diffusivity of the pine apple leaf fibre reinforced composite which means that it could not provide the conductive path to the heat energy in the composite material. Sweeting et al.[6] developed a new experimental method to determine the in-plane through-thickness thermal conductivities of polymer matrix composites. 
Alsina et al. [7] presented the thermal properties of jute-cotton; sisal-cotton and ramie-cotton hybrid reinforced unsaturated polyester composites. The results showed that sisal-cotton hybrid polyester composites have the thermal conductivity $0.213-0.25 \mathrm{~W} / \mathrm{m}-\mathrm{k}$, jute-cotton hybrid polyester composites have the thermal conductivity $0.10-0.237 \mathrm{~W} / \mathrm{m}-\mathrm{k}$, Ramie-cotton hybrid polyester composites have thermal conductivity $0.19-0.22 \mathrm{~W} / \mathrm{m}-\mathrm{k}$. Idicula et al.[8] investigated the thermal conductivity, diffusivity and specific heat of polyester/natural fibre (banana/sisal) composites as function of filler concentration and for several fibre surface treatment. The results showed that chemical treatment of the fibres reduces the composite thermal contact resistance. Behzad and Sain [9] determined the thermal conductivity of the hemp fibre reinforced polymer composite at different volume fractions of the fibre. To confirm the experimental results, the heating experiments are simulated by a finite element model (FEM) using the thermal conductivity values obtained from the experiment and found good agreement between the obtained results and models. Sherely et al.[10] worked on the periodical method to estimate the thermal conductivity, thermal diffusivity of polypropylene /banana polypropylene/banana fibre composites at room temperature. It was found that the thermal conductivity and thermal diffusivity of composite decreased with fibre loading. Li et al. [11] determined the various thermal properties, namely, thermal conductivity, thermal diffusivity and specific heat of flax fibre-HDPE bicomposites around $170-200^{\circ} \mathrm{C}$ temperature range. The thermal conductivity. thermal diffusivity and specific heat found to be decreased with increase in fibre content; however, there is no appreciable change in thermal conductivity as well as thermal diffusivity in the specified temperature range. Holotescu et al.[12] presented an empirical model for the effective thermal conductivity of a polymer composite that includes dependency on the filler size distribution. The validation of new model and its characteristic equation was carried out using experimental data from the reference. Mounika et al.[13] investigated the thermal conductivity characterization experimentally by a guarded heat flow meter method. The results showed that the thermal conductivity of the composite decreased with increase in fibre content and quite opposite trend was observed with respect to temperature. Raju et al.[14] aimed to elucidate the optimization of thermal properties such as thermal conductivity, linear thermal expansion and specific heat of ground nut shell particles reinforced polymer composite materials. Using ground nut shell particles as reinforcement for polymer matrix could successfully develop beneficial composites and can be used for thermal applications. Dedeepya et al.[15] measured mechanical properties of composite such as tensile strength, tensile modulus using universal testing machine and thermal conductivity of natural fibre typha angustifolia reinforced composite using Guarded hot plate apparatus. It was observed that mechanical properties increased as fibre content increased and thermal conductivity decreased as fibre content increased

\section{Thermal Conductivity Models}

Many theoretical and empirical models have been proposed to predict the effective thermal conductivity of two phase mixtures. For a two component composite the simplest alternative would be with the materials arranged in either parallel or series with respect to heat flow, which gives the upper and lower bounds of effective thermal conductivity (Eqns.1 and 2).

\section{Series Model (Rule of Mixture):}

$$
\frac{1}{K_{c}}=\frac{1-\phi}{K_{m}}+\frac{\phi}{K_{f}}
$$

Where c- composite, m- matrix, f-filler, $\Phi$ - volume fraction

\section{Parallel model:}

$$
K_{c}=(1-\phi) K_{m}+\phi K_{f}
$$

Where $K_{c}$ - Thermal conductivity of composite, $\mathrm{K}_{\mathrm{m}}$ - Thermal conductivity of matrix, $\mathrm{K}_{\mathrm{f}^{-}}$Thermal conductivity of filler and $\Phi$ - is the volume fraction of the filler.

In fact, one can use the series model or parallel model alone or both models according to the practical circumstances. Maxwell [1] using potential theory obtained an exact solution for the conductivity of randomly distributed and non-interacting homogeneous sphere in homogeneous medium as indicated in Eqn.3.

$$
K_{c}=K_{m}\left[\frac{K_{f}+2 K_{m}+2 \phi\left(K_{f}-K_{m}\right)}{K_{f}+2 K_{m}-\phi\left(K_{f}-K_{m}\right)}\right]
$$

\section{Experimental Details}

\subsection{Matrix Material (Polyester)}

Unsaturated polyester resin of grade ECMALON 4411 and the corresponding hardener are mixed in a ratio of 98:2 by weight supplied by Ecmass Resin (Pvt) Ltd, Hyderabad, India. The resin has a density of $1.242 \mathrm{~g} / \mathrm{cc}$, Young's modulus of $615 \mathrm{MPa}$, Tensile strength of $29.2 \mathrm{Mpa}$ and elongation at break of $4.5 \%$. 


\subsection{Fibre Material (Palm fibre)}

Palm fibres from matured tree and top portion of leaves have been collected from the small scale industries of Narsipatnam of Visakhapatnam district, Andhra Pradesh, India as filler material for its light weight and durability. It is also renewable, eco-friendly, available at low cost and basically considered as waste product. The length and diameter of chopped fibres are $20 \mathrm{~mm}$ and 19.7 microns respectively. The mechanical properties of these fibres are:
i. $\quad$ Density- $0.33 \mathrm{gm} / \mathrm{cm} 3$
ii. Tensile strength- $24.1 \mathrm{MPa}$
ii. Young's modulus- $844.18 \mathrm{MPa}$

\subsection{Composite Preparation}

The unsaturated polyester and corresponding hardener were mixed in a ratio of $98: 2$ by weight as recommended. Chopped Palm fibres of above sizes were reinforced in polyester resin $(1.242 \mathrm{~g} / \mathrm{cc})$ to prepare the composite. Hand-lay-up technique was used for preparation of the specimen (sample) with different volume fractions $(6.5 \mathrm{vol} \%, 11.3 \mathrm{vol} \%, 26.8 \mathrm{vol} \%$ and $35.9 \mathrm{vol} \%)$. A stainless steel mould having dimensions of $200 \times 200 \times 10 \mathrm{~mm}$ was used for this purpose. Silicon spray was used to facilitate easy removal of the composite from the mould after curing. The cast of each composite was cured under a load of about 50kg for 24 hours before it was removed from the mould. Then this cast was post cured in air for another 24 hours. The specimens were prepared having diameter of $40 \mathrm{~mm}$ with thickness of $4 \mathrm{~mm}$ as shown in Fig. 1 and2..

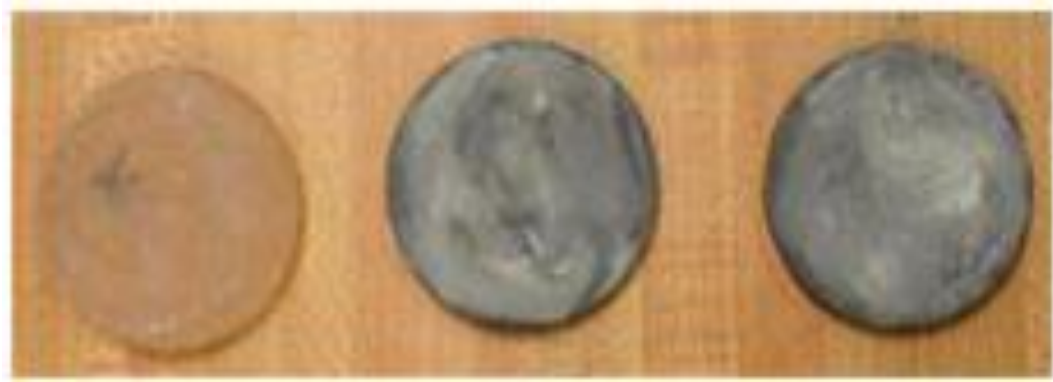

Fig.1 Specimens for thermal conductivity measurement

\subsection{Experimental set up}

The thermal conductivity test is carried out with Lee's disc apparatus shown in Fig- 3. The brass disc (B) is hung from the stand with the help of three strings. On the brass disc (B), sample $\operatorname{disc}(\mathrm{S})$ is placed. Metallic disc (M) is placed on the top of the sample disc. On the metallic disc $(\mathrm{M})$ a heating chamber $(\mathrm{H})$ with facility of passage of steam in and out is created. Two holes are made in the brass disc (B) and metallic disc (M) for the insertion of thermometers to measure the temperature.

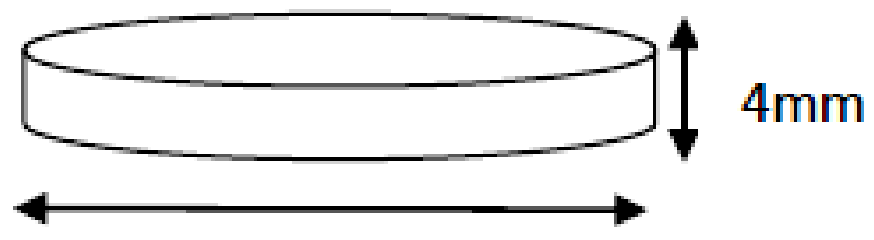

\section{$40 \mathrm{~mm}$}

Fig.2 Standard dimensions of specimen

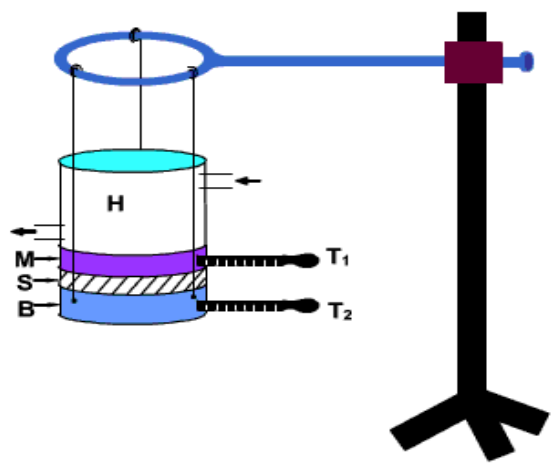

Fig .3 Lee's disc apparatus 


\subsection{Working procedure}

- Mass of the brass disc (B) is measured using a balance. Diameter of the specimen or sample is measured using vernier caliper. Thickness of the specimen or sample is measured using a screw gauge.

- The heater $(\mathrm{H})$ is started by sending steam through the heating chamber. The temperatures $T_{1}$ and $T_{2}$ are recorded at a regular interval of 5 minutes till they reached the steady state.

- Then, the supply of steam is cut off and upper metallic disc (M) and specimen or sample disc (S) are removed. Steam is again passed in so that the brass disc is heated to a temperature $10^{\circ} \mathrm{C}$ above the steady state temperature $\mathrm{T}_{2}$. After that the heating chamber is removed and allowed the brass disc (B) to cool. Temperature is noted in every half a minute until the temperature falls about $10^{\circ} \mathrm{C}$ from steady state temperature $\mathrm{T}_{2}$.

- Graph is drawn with the time of cooling as abscissa and the temperature of brass disc (B) as ordinate. A tangent is drawn at the steady state temperature $\mathrm{T}_{2}$. The slope of this tangent gives the rate of cooling $\partial T / \partial t$ at steady state temperature $T_{2}$.

\subsection{Thermal conductivity measurement}

Thermal conductivity is a material property that describes the rate at which the heat flows within a body for a given temperature change.

The rate of heat conducted through the specimen or sample is

$Q=K A\left(T_{1}-T_{2}\right) / L$

Where, $\mathrm{L}$ is the thickness of the sample, $\mathrm{A}$ is the area of cross section of the sample, $\mathrm{K}$ is the thermal conductivity, $\mathrm{Q}$ is the rate of heat transfer and $\left(\mathrm{T}_{1}-\mathrm{T}_{2}\right)$ is the temperature difference.

The rate of heat lost by the brass disc (B) to the surrounding under steady state is

$$
Q=m c(\partial T / \partial t)_{T_{2}}
$$

Where, $\mathrm{m}$ is the mass of brass disc (B), $\mathrm{c}$ is the specific heat of the brass disc (B) and ( $\partial T / \partial t)$ is it's rate of cooling at $\mathrm{T}_{2}$

Comparing equation (4) and (5)

$$
K=m c(\partial T / \partial t)_{T_{2}} / A\left(T_{1}-T_{2}\right) / L
$$

$(\partial T / \partial t)_{T_{2}}$ and $\left(\mathrm{T}_{1}-\mathrm{T}_{2}\right)$ is calculated using Lee's disc apparatus. Giving the input value of mass of brass disc (B), specific heat of the brass disc, thickness of the sample and area of cross section of the of the sample, the thermal conductivity of the sample is calculated.

\section{Results and discussion}

The effective thermal conductivity values obtained from the experimental study for the particulate filled polyester composites with varied proportion of palm fibre are compared with Rule of mixture thermal conductivity model, parallel thermal conductivity model and Maxwell thermal conductivity model ( Fig.4). It is noticed that the experimental results and all three models are close to each other at low fibre content. It has been found that the thermal conductivity of experimental study and all other three models are increased with increase of fibre contents. On comparison, it has been found that the errors associated with Rule of mixture model, Parallel model and Maxwell correlations with respect to experimental ones lie in the range of 33.25 to $79.2 \%$, 28.5 to $73.2 \%$ and 31 to $75.2 \%$ respectively. The values of thermal conductivities and percentage of errors associated with each method for individual composite with two components i.e polyester and palm fibre are given in Table-1 and Table-2 respectively.

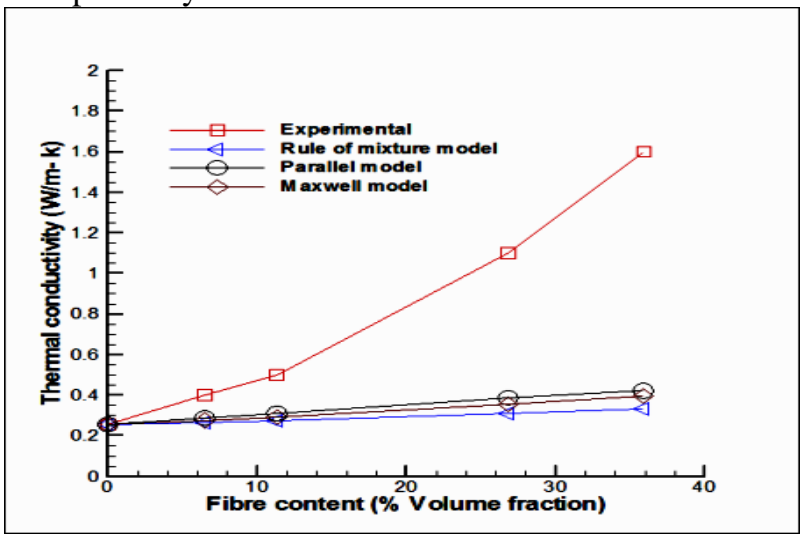

Fig.4. Thermal conductivity values for different models 
Table 1 Thermal conductivity values of composites obtained from different methods

\begin{tabular}{|c|c|c|c|c|c|}
\hline \multirow[b]{2}{*}{ Sample } & \multirow{2}{*}{$\begin{array}{l}\text { Fibre } \\
\text { Content } \\
(\text { Vol \%) }\end{array}$} & \multicolumn{4}{|c|}{ Effective thermal conductivity of composites(W/m- k) } \\
\hline & & $\begin{array}{l}\text { Rule of } \\
\text { mixture } \\
\text { model }\end{array}$ & $\begin{array}{l}\text { Parallel } \\
\text { model }\end{array}$ & $\begin{array}{l}\text { Maxwell } \\
\text { model }\end{array}$ & Experimental \\
\hline $\mathbf{1}$ & 0 & 0.255 & 0.255 & 0.255 & 0.255 \\
\hline 2 & 6.5 & 0.267 & 0.286 & 0.276 & 0.400 \\
\hline 3 & 11.3 & 0.275 & 0.310 & 0.294 & 0.500 \\
\hline 4 & 26.8 & 0.309 & 0.386 & 0.356 & 1.100 \\
\hline 5 & 35.9 & $\mathbf{0 . 3 3 3}$ & 0.429 & 0.397 & 1.600 \\
\hline
\end{tabular}

Table 2 Percentage errors with respect to the measured value

\begin{tabular}{|l|l|l|l|l|}
\hline \multirow{2}{*}{ Sample } & \multirow{2}{*}{$\begin{array}{l}\text { Fibre Content } \\
\text { (Vol \%) }\end{array}$} & \multicolumn{2}{|l|}{$\begin{array}{l}\text { Percentage errors with } \\
\text { Experimental values }\end{array}$} \\
\cline { 3 - 5 } & $\begin{array}{l}\text { Rule of } \begin{array}{l}\text { respect to } \\
\text { mixture } \\
\text { model }\end{array} \\
\text { Parallel } \\
\text { model }\end{array}$ & $\begin{array}{l}\text { Maxwell } \\
\text { model }\end{array}$ \\
\hline 1 & $0($ Polvester) & 0 & 0 & 0 \\
\hline 3 & 6.5 & 33.25 & 28.50 & 31.00 \\
\hline 4 & 11.3 & 45.00 & 38.00 & 41.20 \\
\hline 5 & 26.8 & 71.90 & 64.90 & 67.60 \\
\hline
\end{tabular}

\section{Conclusions}

- An environmental waste like palm-fibre can be gainfully utilized for preparation of composites.

- Composites made of palm-fibre posses less thermal conductivity and this can be used as insulators.

- It has been found that the thermal conductivity of composites made of palm-fibre is increased with increase of fibre content.

- With light weight and good thermal properties, the palm-fibre reinforced polyester composite can be used for preparation of insulation boards, air craft components and furnitures etc.

- At low fibre percentage i.e sample 2 and 3 the results are in close range to each other.

- However with increased fibre content (samples 4 and 5) the error is more for all the models as compared to experimental results.

\section{References}

[1] Maxwell J.C., "A Treaties on Electricity and Magnetism," $3^{\text {rd }}$ Ed. New York: Dover, 1954.

[2] Agrawal, R., Saxeena, N.S., Sreekala, M.S., and Thomas, S., "Effect of Treatment on the Thermal Conductivity and Thermal Diffusivity of Oil Palm Fibre Reinforced Phenol FormaldehydeComposites," Jou. Polym. Sci. B. Vol. 38, 2000 , pp. 916-921.

[3] Saxena, N. S., Agarwal, R., Sharma, K. B., Thomas, S. and Pathan, L. A., "Thermal Conduction and Diffusion Through GlassBanana Fibre Polyester Composites,” Ind. J. Pure Appl. Phys., Vol.41 (6), 2003, pp. 448-452.

[4] Fu, S. Y. and Mai, Y.W., "Thermal Conductivity of Misaligned Short Fibre Reinforced Polymer Composites," J. Appl. Polymer Sci., Vol. (88), 2003, pp. 1497-1505.

[5] Mangal, R., Saxena, N. S., Sreekala, M., S., Thomas and Singh, K., "Thermal Properties of Pine Apple Leaf Fibre Reinforced Composites," Aterial Sci, Eng., Vol. 339 (1), 2003, pp. 281-285.

[6] Sweeting, R. D. and Liu, X. L, "Measurement of Thermal Conductivity for Fibre Reinforced Composites," Cmposite A: Appl. Sci. Manuf., Vol. 35 (7), 2004, pp. 933-938.

[7] Alsina, OLS, de Carvalho, LH, Ramos Filho, FG, d Almeida. JRM, "Thermal Properties of Hybrid Lingo Cellulosic Fabric Reinforced Polyester Matrix Composites,” Journal of Polymer Testing, Vol. 24, 2005, pp. 81-85.

[8] Idicula M., Boudenne A., Umadevi L., Ibos L..Candau Y. and Thomas S., "Thermo Physical Properties of Natural Fibre Reinforced Polyester Composites," Composite Sci. Tecnology, Vol. 66, 2006, pp. 2719-2725.

[9] Behzad, T. and Sain, M., "Measurement and Prediction of Thermal Conductivity for Hemp Fibre Reinforced Composites," Polymer Eng. Sci. Vol. 47 (7), 2007, pp.977-983.

[10] Sherely, A. P., Boudenn, A., Ibos, L., Candau, Y., Joseph, K. and Thomas, S., "Thermo Physical Properties of Banana Fibre/ Polypropylene Commingled Composite Materials," Composites Part A, Vol. 39, 2008, pp.1582-1588.

[11] Li, X., Tabil, L. G., Wuka, I., Oguocha, N. and Panigrahi, S. N., "Thermal Conductivity, Thermal Diffusivity and Specific Heat of Flax fibre-HDPE Biocomposites at Processing Temperatures," Journal of Composite Science and Technology, Vol. 68 (7), 2008, pp 1753-1758.

[12] Holotescu, S. and Stoin, F. D., "Evaluation of the Effective Thermal Conductivity of Composite Polymers by Considering the Filler Size Distribution Law,” Journal of Zhejiang University Science A, Vol. 10 (5), 2009, pp 704- 709.

[13] Mounika, M., Ramaniah, K., Ratnaprasad, A. V., Rao, K. M. and Reddy, K. H. C., "Thermal Conductivity Characterization of Bamboo Fibre Reinforced Polyester Composites,” J. Mater. Environ.Sci., Vol. 3 (6), 2012, pp. 1109- 1116.

[14] Raju, G.U.. Gaitonde, V.N.and Kumarappa, S., “ Experimental Study on Optimization of Thermal Properties of Ground nut shell Particle Reinforced Polymer Composites,” Int. J. Emerg. Sci., Vol. 2 (3), 2012, pp. 433-454.

[15] Dedeepya, M., Raju, T.D., and Kumar, T.D., "Effect of Alkaline Treatment on Mechanical and Thermal Properties Oftypha Angustipolia Fibre Reinforced Composites," IJMIE, Vol. 1(4), 2012, pp. 12-14. 